\title{
Orignial article
}

\section{Personal smartphones for neonatal diagnostic imaging: a prospective crossover study.}

Abbreviations

CXR Chest x-ray

JPEG joint photographic experts group format

MMS multimedia messaging service

NPV negative predictive value

PACS picture archiving and communications system

PIPER Paediatric Infant Perinatal Emergency Retrieval

PPV positive predictive value

RCH The Royal Children's Hospital

RWH The Royal Women's Hospital

\section{Author contributions:}

TV and MW equally collected and analysed data and wrote the first draft

MT and RB conceived and designed study, edited manuscript.

SD supervised data analysis, edited manuscript

This is the author manuscript accepted for publication and has undergone full peer review but has not been through the copyediting, typesetting, pagination and proofreading process, which may lead to differences between this version and the Version of Record. Please cite this article as doi: 10.1111/jpc.13467

This article is protected by copyright. All rights reserved. 
PGD designed study, edited manuscript

JAD designed study, supervised all components of the study edited and submitted the final paper

All authors approved the final version of the manuscript.

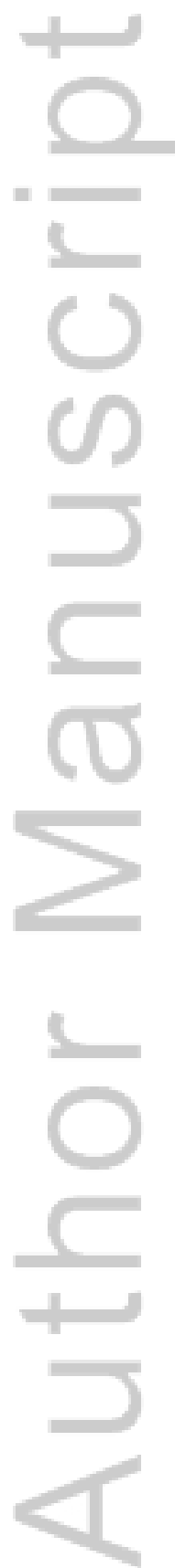

This article is protected by copyright. All rights reserved. 


\section{ABSTRACT}

Aim: Neonatal clinicians may be asked to review x-ray images when unable to directly access the original image. Transmitting an x-ray image to a smartphone is a technique increasingly being used by clinicians in a number of settings. Minimal data exists on its use in the neonatal setting. Our aim was to compare the ability of neonatal clinicians to correctly diagnose a pneumothorax from a chest radiograph (CXR) viewed on a smartphone, paralleled with the same image viewed on a computer screen.

Method: We investigated the accuracy, sensitivity, specificity, positive predictive value, and negative predicative value of two methods of viewing CXR images to diagnose pneumothorax, compared with a gold standard radiologist report. Clinicians were presented with 40 CXR images on two occasions, at least one week apart. Images were viewed once on a smartphone and once on a computer screen. Both the viewing method and viewing order of the images were randomised. The clinical details of the infant at the time the CXR was taken were provided, and participants were asked if a pneumothorax was present.

Results: Twenty-one clinicians viewed all CXR images using both viewing methods (840 paired observations). There was no difference in accuracy of detecting pneumothorax between viewing methods, $81 \%$ correctly identified a pneumothorax using the smartphone, vs. $80 \%$ using the computer screen $(\mathrm{p}=0.40(95 \% \mathrm{CI})$, difference -4 to $1.5 \%)$

This article is protected by copyright. All rights reserved. 
Conclusion: Diagnosis of neonatal pneumothorax was as accurate using a smartphone as viewing CXR images displayed on a computer screen when clinicians were presented with x-rays with diagnosis of pneumothorax.

Key words: infant,newborn; teleradiology; diagnostic accuracy; pneumothorax, smartphone.

\section{INTRODUCTION}

Telemedicine is increasingly being used by clinicians in a number of clinical settings. The World Health Organization (WHO) defines telemedicine as the communication or consultation between health professionals about patients using the voice, text, data, imaging, or video functions of a mobile device ${ }^{1}$. The accuracy of smartphones and tablets for viewing radiologic images remotely via a mobile (cellular) telephone to view radiographs has been shown to be useful to diagnose fractures ${ }^{2-6}$ in adult patients. It has been used less often to diagnose, intracranial bleeds ${ }^{7}$, pneumonia ${ }^{8,9}$; appendicitis ${ }^{10}$, common skin conditions ${ }^{11}$ and stroke ${ }^{12}$. Telemedicine may be used by neonatal clinicians to diagnose pathology from an infant's X-ray sent via multimedia messaging service (MMS) to a remotely-sited clinician's smartphone or tablet. In response to the growing use of telemedicine the Australian Medical Association (AMA) in 2014 produced guidelines that included recommendations regarding clinical images and the use of personal mobile devices. The AMA defined a clinical image as including a picture of a diagnostic image i.e. an x-ray ${ }^{13}$. 
There is a paucity of evidence to determine whether current-generation smartphones have sufficient image resolution to correctly identify important neonatal conditions, such as pneumothoraces, pneumonia, meconium aspiration syndrome, atelectasis, pneumatosis intestinalis and abdominal perforation. Pneumothorax is associated with increased morbidity and mortality among preterm infants ${ }^{14}$. The aim of this study was to compare the accuracy of diagnosing a pneumothorax by viewing neonatal CXRs using a dedicated imaging program to view x-rays on a computer screen, compared with viewing the same CXRs sent as an image via MMS to a smartphone.

\section{METHOD}

\section{Setting}

The project was completed from September to December 2014 at the Royal Women's Hospital (RWH), Melbourne, Australia and at Paediatric Infant Perinatal Emergency Retrieval, Royal Children's Hospital, (PIPER/RCH) Melbourne, Australia.

\section{Subjects}

Clinicians were recruited from the Neonatal and Intensive and Special Care (NISC)

medical team at RWH and from PIPER/RCH. Participants were asked to view study CXR images using both the computer screen and a smartphone.

\section{Study X-rays}

We searched the NISC database for infants with one of the following primary discharge diagnoses: transient tachypnoea of the newborn (TTN), meconium aspiration syndrome 
(MAS), air-leak, and non-specific respiratory distress. Images were excluded if an intercostal catheter was visible. We also excluded images with a very memorable diagnosis such as diaphragmatic hernia or a fracture.

The CXR images selected for the study were from 40 infants with diagnoses of TTN, MAS, air-leak syndromes such as pneumothorax, pneumomediastinum and pulmonary interstitial emphysema, bronchopulmonary dysplasia (BPD) and non-specific respiratory distress. Twenty images were confirmed to demonstrate pneumothorax, by gold standard (radiologist report confirmed by a study investigator and neonatal consultant, LSO).The pneumothoraces varied in size on CXR and their clinical significance ranged in severity from subtle changes in their clinical presentation to clinical details that were suggestive of tension pneumothoraces. The remaining 20 images demonstrated pathology that did not include pneumothorax but did include respiratory distress syndrome; TTN; BPD; and MAS. The CXR images were all taken with the infant supine and were antero-posterior in orientation. Lateral images were not used.

\section{Smartphone}

The smartphone used in this study was an iPhone 5 (iOs8.1, Apple, Cupertino, CA USA), equipped with an eight megapixel camera and a screen resolution of 1136 x 640 pixels. Images were encoded and transmitted in a joint photographic experts group (JPEG) format. 


\section{Computer}

At the RWH, the picture archiving and communications system (PACS) used to store and retrieve X-rays is SYNAPSE (Fujifilm Corporation, Fujifilm Holdings Corporation,Tokyo, Japan). The computer screens used to view the CXR images were Elite One 800 and Elite Display E231 (Hewlett Packard Palo Alto, CA, USA).

Recommendations by the Royal College of Radiologists for image quality when viewing radiographs compared with the technical details of the viewing screens for the smartphone and computer screen are shown in Table 1.

This article is protected by copyright. All rights reserved. 


\section{Image capture and transmission}

Study CXRs were de-identified, displayed on a computer screen, and the image was captured with a smartphone camera (iPhone 5) without flash, approximately 30 centimetres from the computer screen, using the smartphone camera's autofocus capability. In order to avoid a reflective glare on the computer screen, attempts were made to avoid direct sunlight. In addition, the overhead light in the room was switched off. Images were retaken if there was a reflection or colour shifting on the captured image and were then transmitted to the study smartphone (iPhone 5). Each image was automatically compressed to a $500 \mathrm{~kb}$ sized image.

\section{Study procedure}

CXR images were viewed by participants during two viewing sessions at least one week apart. Viewing sessions were randomised. Images were viewed on the study smartphone during one session and on the computer screen using the imaging software described during the other session. The same smartphone was used by all participants. The order of the images presented to participants at each viewing session was randomised. Participants were able to manipulate the images on both devices. On the smartphone, it was possible to zoom and to rotate the image. When using the computer screen it was possible for participants to zoom, rotate, and adjust brightness and contrast, and invert the images. Participants were unaware of the number of CXRs with a diagnosis of pneumothorax. 
In order to provide the context for the images the participants were given information about the infant's clinical condition at the time the x-ray was taken e.g. gestation, birth weight, postnatal age and presenting signs. For each image participants were asked "Can you see a pneumothorax in this image?" "yes" or "no" were the only possible responses.

\section{Data analysis}

Responses were considered correct if they agreed with the gold standard diagnosis. The sensitivity, specificity, accuracy, positive predictive value (PPV) and negative predictive value (NPV) for each device compared with the gold standard was calculated. We also compared differences between devices using binomial regression accounting for repeated observations by participants.

We assessed sub-groups by birth weight $(<1500 \mathrm{~g}$ vs. $\geq 1500 \mathrm{~g})$, clinical experience (consultants vs. fellows), order of first device used, and previous experience of reviewing x-rays using a smartphone.

Inter-observer reproducibility was assessed using Kappa statistics. We judged agreement to be perfect if $\mathrm{k}=1$ and poor if $\mathrm{k}=0$. Data were analysed using SPSS (IBM SPSS Statistics version 22. Armonk, NY: IBM Corp.).

\section{Sample size}

A pragmatic sample size of 40 images (20 with a pneumothorax, 20 without a pneumothorax), viewed twice by at least 20 participants was chosen. With over 800 
observations for each diagnostic method there was $80 \%$ power to detect a difference of $5 \%$ between diagnostic methods for each of the outcomes (sensitivity, specificity, accuracy, PPV and NPV).

\section{Ethical approval}

We used pre-existing x-rays already available on the RWH database that had been taken for clinical purposes and which were de-identified for the study. The RWH Research and Ethics Committees determined that the study met The National Health and Medical Research Council Australia requirements for quality assurance/audit projects, and gave approval for this study. Agreement by clinicians to participate in the study implied consent.

\section{RESULTS}

Twenty-six clinicians at RWH and PIPER/RCH were approached to participate in the study. Four declined and one did not complete both parts of the study. Twelve consultants (57\%) and nine fellows (43\%) completed the two parts of the study and made 840 paired assessments. Participant's had a mean (standard deviation, SD) of 11.7 (8.5) years of neonatal experience. Before the study more than half of the participants (62\%) said that they had previously reviewed x-rays using a smartphone. The 40 study CXRs were from infants with a mean (SD) birth weight 2750 (1135) grams, and mean (SD) weeks' gestational age 35.6 (5) at the time of the study CXR.

This article is protected by copyright. All rights reserved. 


\section{Primary outcome}

Table 2 shows the accuracy of diagnosing pneumothorax using both methods. There was no statistically significant difference in the accuracy of diagnosing pneumothorax between viewing methods compared with gold standard; smartphone versus gold standard was $81 \%$ accurate vs. computer versus gold standard was $80 \%$ accurate, ( $p=0.40 \mathrm{CI}(95 \%)$, difference -4 to $1.5 \%)$. Viewing the images on the computer screen compared with the smartphone had significantly lower sensitivity (p=0.04 CI (95\%), difference-11 to $21 \%$ ) and higher specificity ( $p=0.04$ CI (95\%), difference -8 to $0.15 \%)$. There were no differences in diagnosing a pneumothorax between the two methods for PPV and NPV.

\section{Secondary outcomes}

There were no significant differences in accuracy in diagnosing a pneumothorax between any of the subgroups; experience, birth weight, device used for the first assessment (data not shown), or participants previous experience in reviewing $\mathrm{x}$-rays using a smartphone (data not shown).

The level of inter-observer agreement in detecting the presence of a pneumothorax on both the smartphone and computer screen was good (kappa $=0.67)$.

\section{DISCUSSION}

This is the first study in neonatology to test the use of teleradiology with x-ray images sent via MMS to a smartphone. We chose pneumothorax to study as it is an important

This article is protected by copyright. All rights reserved. 
cause of neonatal morbidity ${ }^{14}$. We found that there was little difference in the proportion of accurate pneumothorax diagnoses using a smart phone versus viewing the images on a computer screen. Our study is strengthened by the large number of observations and the number of participants who viewed the images.

The importance of our findings is highlighted by the discovery that more than half of the participants had previously used their smartphone to review neonatal x-rays. Using MMS to transmit x-ray images has the potential to improve communication between clinicians. Incorporating it into existing clinical practice could enhance confidence in remote decision making. In Australia, and other parts of the world, infants are born in rural, remote or other non-tertiary perinatal centres. Sending an x-ray image, via MMS, might be the only way a remotely sited clinician has to gain specialist advice.

There are several ways to send an electronic version of an x-ray image between sites. The most direct method is electronic transfer between compatible software systems. However, this is often not possible. Alternatively photographs of x-ray films illuminated on a light box can be sent via MMS. However, the method most commonly reported by clinicians in our region was photographing a CXR image displayed on a computer screen, then sent via MMS to another clinician's smartphone. Therefore we studied this method.

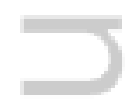

The accuracy of correctly detecting conditions of interest in images sent by MMS to a smartphone compared with a gold standard has been reported as 69 to $98 \% 2,3,7,9,11,15$.

This article is protected by copyright. All rights reserved. 
The highest accuracy rate was achieved in studies identifying fractures ${ }^{3,4}$ and lowest in a study assessing pneumonia in adults ${ }^{8}$.

Our accuracy rate of around $80 \%$ is similar to that found by Schwartz et al ${ }^{9}$ who tested the diagnostic accuracy of radiologists when reviewing CXRs viewed on a light box with digital photographs of plain film CXRs. In this study, seven radiologists were randomised to review 75 plain film CXRs on light boxes before viewing 75 digital photographs, or vice versa. Their responses were considered correct if they matched the pre-defined diagnosis. For plain film CXRs, the correct diagnosis was provided in $82 \%$ of cases and for digital photographs the correct diagnosis was provided in $76 \%$ of cases. To our knowledge, no tested method has achieved 100\% accuracy. Accuracy in our study is likely to be $<100 \%$ because diagnosing neonatal pneumothorax can be difficult ${ }^{16}$ regardless of the media used to review the image.

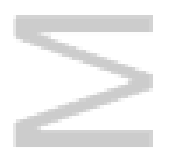

A potential limitation of MMS transmission of radiographs is image quality. Taking and sending images via MMS can result in loss of quality and resolution. Image quality can be influenced by the cellular network or the receiving telephone settings and screen size. Compressing images can also affect image quality. Image quality and accuracy of diagnosis might be different when sending $\mathrm{x}$-ray images via email compared with MMS.

Previous generation smartphones were unable to achieve images with similar quality to that achieved in our study. Early studies which tested the quality of X-ray images sent

This article is protected by copyright. All rights reserved. 
via MMS, found that many images could not be evaluated due to their poor quality, likely because they were captured and sent with a mobile phone equipped with a 1.2 megapixel camera [14]. We used a third generation smartphone with a built in 8megapixel camera. We ensured high quality images by standardising the conditions for image capture (darkened room, camera mode without flash and images captured by the smartphone at $30 \mathrm{~cm}$ from computer screen). In clinical practice it might be difficult to replicate these conditions. Image quality may be further improved when using next generation smartphones which currently use up at least a 12 megapixel camera and have larger screens. We tested a single model of smartphone; other models of smartphones may have resulted in different quality of image and altered accuracy rates. Additionally, we did not test tablet screens, where larger screen size may have improved resolution and accuracy.

In 2012 The Royal College of Radiologists, in their recommendations for viewing images, did not recommend using a handheld device to review images for the purpose of a primary diagnosis ${ }^{17}$. Newer generation handheld devices have more pixels, with better resolution. It is possible that the recommendation may change with improved hand held device image quality.

We minimised memory bias in participants by randomising the order in which participants viewed the study images, by excluding particularly memorable images, and by separating viewing episodes by at least one week. We felt that this would be 
sufficient time to reduce the potential for participants to remember individual x-ray images. We only enrolled neonatal consultants and fellows as these are the clinicians most likely to be asked to use their smartphone to review an x-ray image as part of a discussion on clinical management. A group of less experienced clinicians may achieve different results.

In clinical practice, using MMS to send radiographs raises issues for maintaining patient confidentiality and privacy. In our study we were careful to de-identify the images sent to participants. It may be more difficult to de-identify images when sending them for clinical reasons. Identifiable patient data stored on a clinician's smartphone is potentially vulnerable should the device be lost or stolen. Steps to protect patient identity would need to be considered before any recommendation to use such devices in the routine review of X-ray images were made.

\section{Conclusion}

We have shown that neonatal clinicians were able to adequately identify a pneumothorax from the image of a neonatal chest radiograph transmitted to a smartphone. Whilst we have shown that interpretation of CXR images viewed on smartphones is as accurate for the diagnosis of pneumothorax as images viewed on a computer screen, this may not necessarily true for other diagnoses. Where on-site

This article is protected by copyright. All rights reserved. 
expertise is limited transmitting images of radiographs to a smartphone for off-site consultation may be helpful.

\section{Acknowledgments}

We are grateful to the Data mangers at RWH, Dr Michael Stewart, Medical Director PIPER, and participants in our study for all their help and support.

Competing interests: none.

\section{Funding}

This work was supported by NHMRC Program Grant no 384100. JAD, LSO, and MT are supported by NHMRC Post-Doctoral Fellowships and are supported by the Victorian Government's Operational Infrastructure Support Program. PGD is a recipient of an NHMRC Practitioner Fellowship.

\section{Competing Interest}

None declared.

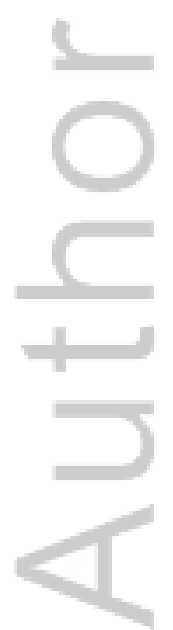

This article is protected by copyright. All rights reserved. 
Table 1 .Description of the technical qualities of the smartphone and the computer system used to view study CXR images.

\begin{tabular}{|l|l|l|l|}
\hline & $\begin{array}{l}\text { Recommendations } \\
\text { for x-ray } \\
\text { interpretation }\end{array}$ & $\begin{array}{l}\text { Smartphone: iPhone } \\
5\end{array}$ & $\begin{array}{l}\text { Computer } \\
\text { screen }\end{array}$ \\
\hline Software & & Apple/iOS 8.1 & PACS Synapse 4.1 \\
\hline Size & 21 inch diagonal & 4 inch diagonal & 23 inch diagonal \\
\hline Resolution & $\begin{array}{l}\min 1024 \times 1024 \\
\text { pixels }\end{array}$ & $1136 \times 640$ pixels & $1920 \times 1080$ pixels \\
\hline Brightness & $\min 350 \mathrm{~cd} / \mathrm{m}^{2}$ & $500 \mathrm{~cd} / \mathrm{m}^{2}$ & $250 \mathrm{~cd} / \mathrm{m}^{2}$ \\
\hline
\end{tabular}

This article is protected by copyright. All rights reserved. 
Table 2. Accuracy of diagnosing pneumothorax by viewing images on a smartphone, compared with viewing images on a computer screen.

\begin{tabular}{|l|c|c|c|l|}
\hline & $\begin{array}{l}\text { Smartphone vs. } \\
\text { gold standard }\end{array}$ & $\begin{array}{l}\text { Computer vs. } \\
\text { gold standard }\end{array}$ & p value & $\begin{array}{l}\text { Difference } \\
\text { between } \\
\text { devices } \\
\text { (95\% CI) }\end{array}$ \\
\hline Accuracy (\%) & 81 & 80 & 0.40 & -4 to $1.5 \%$ \\
\hline Sensitivity (\%) & 79 & 72 & 0.04 & -11 to $21 \%$ \\
\hline Specificity (\%) & 84 & 89 & 0.04 & -8 to $0.15 \%$ \\
\hline PPV (\%) & 83 & 86 & 0.08 & -6 to $0.4 \%$ \\
\hline NPV (\%) & 80 & 76 & 0.05 & 0.04 to $8 \%$ \\
\hline
\end{tabular}

Data are expressed as percentages (\%). $\mathrm{PPV}=$ positive predictive value; $\mathrm{NPV}=$ negative predictive value; $\mathrm{CI}=$ confidence interval.

This article is protected by copyright. All rights reserved. 


\section{What is already known on this topic}

- Smartphones are widely used by clinicians

- Smartphones can be used to transfer radiographic images via multimedia messaging service (MMS)

\section{What this study adds}

- Diagnosis of neonatal pneumothorax is as accurate using a smartphone as viewing CXR images displayed on a computer screen when clinicians are presented with x-rays demonstrating a pneumothorax.

This article is protected by copyright. All rights reserved. 


\section{References}

[1] World Health Organization mHealth: New horizons for health through mobile technologies: second global survey on eHealth. WHO Press, Switzerland; 2011. p. 5-34. http://www.who.int/goe/publications/goe_mhealth_web.pdf. Accesse 8/6/2016 [2] Chandhanayingyong C, Tangtrakulwanich B, Kiriratnikom T. Teleconsultation for emergency orthopaedic patients using the multimedia messaging service via mobile phones. J Telemed Telecare. 2007;13:193-6.

[3] Eranki V, Munt J, Lim MJ, Atkinson R. Consultation of orthopaedics cases using multimedia messaging services. Open Orthop J. 2010;4:164-8.

[4] Ferrero A, Garavaglia G, Gehri R, Maenza F, Petri GJ, Fusetti C. Analysis of the interand intra-observer agreement in radiographic evaluation of wrist fractures using the multimedia messaging service. Hand (N Y). 2011;6:384-9.

[5] Naqvi GA, Daly M, Dawood A, Kurkuri A, Kutty S. Smart consultation for musculoskeletal trauma: accuracy of using smart phones for fracture diagnosis. Surgeon. 2014;12:32-4.

[6] Tennant JN, Shankar V, Dirschl DR. Reliability and validity of a mobile phone for radiographic assessment of ankle injuries: a randomized inter- and intraobserver agreement study. Foot Ankle Int. 2013;34:228-33.

[7] Toomey RJ, Ryan JT, McEntee MF, Evanoff MG, Chakraborty DP, McNulty JP, et al. Diagnostic efficacy of handheld devices for emergency radiologic consultation. Am J Roentgenol. 2010;194:469-74.

This article is protected by copyright. All rights reserved. 
[8] Loeb MB, Carusone SB, Marrie TJ, Brazil K, Krueger P, Lohfeld L, et al. Interobserver reliability of radiologists' interpretations of mobile chest radiographs for nursing homeacquired pneumonia. J Am Med Dir Assoc. 2006;7:416-9.

[9] Schwartz AB, Siddiqui G, Barbieri JS, Akhtar AL, Kim W, Littman-Quinn R, et al. The accuracy of mobile teleradiology in the evaluation of chest X-rays. J Telemed Telecare. $2014 ; 20: 460-3$.

[10] Seong NJ, Kim B, Lee S, Park HS, Kim HJ, Woo H, et al. Off-site smartphone reading of CT images for patients with inconclusive diagnoses of appendicitis from on-call radiologists. Am J Roentgenol. 2014;203:3-9.

[11] Shin H, Kim DH, Ryu HH, Yoon SY, Jo SJ. Teledermatology consultation using a smartphone multimedia messaging service for common skin diseases in the Korean army: a clinical evaluation of its diagnostic accuracy. J Telemed Telecare. 2014;20:70-4. [12] Demaerschalk BM, Vegunta S, Vargas BB, Wu Q, Channer DD, Hentz JG. Reliability of real-time video smartphone for assessing National Institutes of Health Stroke Scale scores in acute stroke patients. Stroke. 2012;43:3271-7.

[13] Australian Medical Association (AMA) and the Medical Indemnity Industry Association of Australia (MIIAA). Clinical images and the use of personal mobile devices. A guide for medical students and doctors. 2014. https://ama.com.au/article/clinicalimages-and-use-personal-mobile-devices.accessed 8/9/2016

[14] Bhatia R, Davis PG, Doyle LW, Wong C, Morley CJ. Identification of pneumothorax in very preterm infants. J Pediatr. 2011;159:115-20 e1.

This article is protected by copyright. All rights reserved. 
[15] Eze N, Lo S, Bray D, Toma AG. The use of camera mobile phone to assess emergency ENT radiological investigations. Clin Otolaryngol. 2005;30:230-3; discussion 3.

[16] Cizmeci MN, Akin K, Kanburoglu MK, Akelma AZ, Andan H, Erbukucu O, et al. The utility of special radiological signs on routinely obtained supine anteroposterior chest radiographs for the early recognition of neonatal pneumothorax. Neonatology. 2013;104:305-11.

[17] The Royal College of Radiologists . Picture achiving and communication systems (PACS) and quality assurance. Second edition . London: The Royal College of Radiologists; 2012.

[18] Faculty of Clinical Radiology. Standards of practice for diagnoist and interventional radiology, V10. The Royal Australian and New Zealand College of Radiologists; 2014. http://www.ranzcr.edu.au/quality-a-safety/radiology/standards-of-practice. Accessed $8 / 6 / 2016$

This article is protected by copyright. All rights reserved. 


\section{University Library}

\section{- M M N E R VA A gateway to Melbourne's research publications}

Minerva Access is the Institutional Repository of The University of Melbourne

Author/s:

Westberg, M;Vasko, T;Owen, LS;Bhatia, R;Lluch, MT;Donath, S;Davis, PG;Dawson, JA

Title:

Personal smartphones for neonatal diagnostic imaging: A prospective crossover study

Date:

2017-04-01

Citation:

Westberg, M., Vasko, T., Owen, L. S., Bhatia, R., Lluch, M. T., Donath, S., Davis, P. G. \& Dawson, J. A. (2017). Personal smartphones for neonatal diagnostic imaging: A prospective crossover study. JOURNAL OF PAEDIATRICS AND CHILD HEALTH, 53 (4), pp.343-347. https://doi.org/10.1111/jpc. 13467.

Persistent Link:

http://hdl.handle.net/11343/292443 